\title{
Overestimated solar water splitting performance on oxide semiconductor anodes
}

\author{
Tuo Wang ${ }^{1,2}$ and Jinlong Gong ${ }^{1,2^{*}}$
}

Water oxidation is a 4-electron uphill energy process that largely limits the overall water splitting reaction thermodynamically and kinetically [1]. Photocurrent measurement is one of the most important approaches to evaluate the performance of a photoanode. It has been well realized that photocurrent may render exaggerated performance when photocorrosion of electrode occurs, such as the case of $\mathrm{ZnO}$ and CdS or when sacrificial reagents are present in the electrolyte. However, the choice of electrolyte could be another very important but easily overlooked issue for the valid interpretation of photocurrent.

Pioneering findings by Choi [2,3] and Mi [4,5] have demonstrated the existence of competing side reactions in various aqueous and non-aqueous electrolytes using $\mathrm{WO}_{3}$ as the photoanode, where the actual $\mathrm{O}_{2}$ evolution amount was measured and compared with photocurrent. It has been shown that the side reaction is more of a problem when 1) acidic or neutral aqueous electrolyte is used;2) the photoanode semiconductor possesses a low valence band (VB) edge that generates highly oxidative holes. When acidic anions, such as $\mathrm{Cl}^{-}, \mathrm{HSO}_{4}{ }^{-}, \mathrm{SO}_{4}{ }^{2-}, \mathrm{ClO}_{4}{ }^{-}$exist in the aqueous electrolyte, the oxidation of these anions will compete with the oxygen evolution reaction (OER) for photogenerated holes. The oxidation of many acidic anions is thermodynamically less favourable than the OER, thus these competing side reactions are rarely of a concern for an electrolysis system in the dark. Under illumination, however, photogenerated holes would have enough energy to overcome the overpotential for the oxidation of acidic anions when the anode semiconductors possess the VB edges low enough to generate highly oxidative holes [3]. In addition, these competing side reactions are kinetically more favourable than the sluggish 4-electron $\mathrm{O}_{2}$ evolution process. For $\mathrm{TiO}_{2}$ photoanode, lower $\mathrm{O}_{2}$ evolution amount compared with the amount calculated from photocurrent was also reported with $\mathrm{O}_{2}$ Faradaic efficiencies of 9\%-35\% in $0.2 \mathrm{~mol} \mathrm{~L}^{-1} \mathrm{H}_{2} \mathrm{SO}_{4}$ under Xe arc lamp illumination [6]. In this consideration, it might be misleading to evaluate the performance of a photocatalytic water oxidation system without measuring the actual $\mathrm{O}_{2}$ evolution rate.

Recently, Niederberger and colleagues [7] have clearly pointed out this important yet easily overlooked issue for photoelectrochemical water splitting, i.e., photocurrent alone is insufficient to fully evaluate the performance of a photoanode. In their experiments, four aqueous electrolytes $\left(1 \mathrm{~mol} \mathrm{~L}^{-1} \mathrm{CH}_{3} \mathrm{SO}_{3} \mathrm{H}, 1 \mathrm{~mol} \mathrm{~L}^{-1} \mathrm{H}_{2} \mathrm{SO}_{4}, 0.1\right.$ mol L ${ }^{-1} \mathrm{Na}_{2} \mathrm{SO}_{4}$ at $\mathrm{pH} 3$, and $0.1 \mathrm{~mol} \mathrm{~L}^{-1} \mathrm{Na}_{2} \mathrm{SO}_{4}$ at $\mathrm{pH}$ 5.5) were used to explore the influence of the competing reactions over the OER on $\mathrm{WO}_{3}$ photoanodes. The $\mathrm{WO}_{3}$ photoanodes prepared from the same condition exhibited noticeably different photocurrent density-potential characteristics in these four aqueous electrolytes under AM 1.5G illumination. When $1 \mathrm{~mol} \mathrm{~L}^{-1} \mathrm{CH}_{3} \mathrm{SO}_{3} \mathrm{H}$ was used as the electrolyte, a photocurrent density of $3.5 \mathrm{~mA} \mathrm{~cm} \mathrm{~cm}^{-2}$ at $1.23 \mathrm{~V}$ vs. reversible hydrogen electrode (RHE) was achieved, followed by $3.2 \mathrm{~mA} \mathrm{~cm}^{-2}$ in $1 \mathrm{~mol} \mathrm{~L}^{-1} \mathrm{H}_{2} \mathrm{SO}_{4}$, $2.4 \mathrm{~mA} \mathrm{~cm}^{-2}$ in $0.1 \mathrm{~mol} \mathrm{~L}^{-1} \mathrm{Na}_{2} \mathrm{SO}_{4}(\mathrm{pH} \mathrm{3})$, and $2.0 \mathrm{~mA}$ $\mathrm{cm}^{-2}$ in $0.1 \mathrm{~mol} \mathrm{~L}^{-1} \mathrm{Na}_{2} \mathrm{SO}_{4}$ (pH 5.5), respectively, at $1.23 \mathrm{~V}$ vs. RHE. This significant photocurrent difference clearly suggests that different surface reactions are involved in these four electrolytes on the same photoanode material.

To reveal the actual reaction pathway, the authors measured the $\mathrm{O}_{2}$ evolution rate, which could be compared with the theoretical $\mathrm{O}_{2}$ evolution amount calculated from the

\footnotetext{
${ }^{1}$ Key Laboratory for Green Chemical Technology of Ministry of Education, School of Chemical Engineering and Technology, Tianjin University, Tianjin 300072, China

${ }^{2}$ Collaborative Innovation Center of Chemical Science and Engineering, Tianjin 300072, China

*Email: jlgong@tju.edu.cn
} 
photocurrent. When $1 \mathrm{~mol} \mathrm{~L}^{-1} \mathrm{CH}_{3} \mathrm{SO}_{3} \mathrm{H}$ was used as the electrolyte, no $\mathrm{O}_{2}$ was observed (Fig. 1a), indicating the absence of water oxidation reaction in spite of the high photocurrent. When $1 \mathrm{~mol} \mathrm{~L}^{-1} \mathrm{H}_{2} \mathrm{SO}_{4}$ was used as the electrolyte, which yielded the second highest photocurrent, $\mathrm{O}_{2}$ could be detected, but with a very slow evolution rate compared to the theoretical value calculated from the photocurrent (Fig. 1b). The resulting $\mathrm{O}_{2}$ Faradaic efficiency is only $8 \%$ for $\mathrm{WO}_{3}$ anode in $1 \mathrm{~mol} \mathrm{~L}^{-1} \mathrm{H}_{2} \mathrm{SO}_{4}$. Compared the high photocurrent and the zero or extremely low $\mathrm{O}_{2}$ evolution rate for $\mathrm{WO}_{3}$ anodes in $\mathrm{CH}_{3} \mathrm{SO}_{3} \mathrm{H}$ and $\mathrm{H}_{2} \mathrm{SO}_{4}$, it can be inferred that serious side reactions exist, which largely suppress the OER and consume the majority of photogenerated holes. Specifically, $\mathrm{CH}_{3} \mathrm{SO}_{3}{ }^{-}$anions could be oxidized to $\mathrm{CH}_{3}\left(\mathrm{SO}_{3}\right)_{2}$ in $1 \mathrm{~mol} \mathrm{~L}^{-1} \mathrm{CH}_{3} \mathrm{SO}_{3} \mathrm{H}$, and $\mathrm{HSO}_{4}^{-}$anions to $\mathrm{S}_{2} \mathrm{O}_{8}{ }^{2-}$ in $1 \mathrm{~mol} \mathrm{~L}^{-1} \mathrm{H}_{2} \mathrm{SO}_{4}$. In this sense, it could be misleading to evaluate the performance of the $\mathrm{WO}_{3}$ photoanode simply using photocurrent as the only indicator.

Lewis and co-works [5] have systematically investigated the photoelectrochemical oxidation of acidic anions. The electrochemical redox potential for $\mathrm{HSO}_{4}{ }^{-}$oxidation, $E^{0}\left(\mathrm{HSO}_{4}{ }^{-} / \mathrm{S}_{2} \mathrm{O}_{8}{ }^{2-}\right)$, equals to $2.12 \mathrm{~V}$ vs. normal hydrogen electrode (NHE), while $E^{0}\left(\mathrm{CH}_{3} \mathrm{SO}_{3}{ }^{-} /\left(\mathrm{CH}_{3} \mathrm{SO}_{3}\right)_{2}\right)$ was predicted to be less than $2.12 \mathrm{~V} v$ s. NHE. Although water oxidation $\left(E^{0}\left(\mathrm{O}_{2} / \mathrm{H}_{2} \mathrm{O}\right)=1.23 \mathrm{~V}\right.$ vs. $\left.\mathrm{NHE}\right)$ is thermodynamically more favourable than the oxidation of $\mathrm{HSO}_{4}^{-}$ and $\mathrm{CH}_{3} \mathrm{SO}_{3}^{-}$anions, the 4-electron OER is kinetically hindered. In addition, the low $\mathrm{VB}$ edge of $\mathrm{WO}_{3}$ makes it possible for photogenerated holes to overcome the overpotential for these two competing reactions. Thus, the $\mathrm{O}_{2}$ evolution is largely suppressed in $\mathrm{CH}_{3} \mathrm{SO}_{3} \mathrm{H}$ and $\mathrm{H}_{2} \mathrm{SO}_{4}$ electrolytes when using $\mathrm{WO}_{3}$ as the photoanodes. Similarly, the oxidation of $\mathrm{Cl}^{-}$anion will completely suppress water oxidation owing to the relatively low redox potential of this 2-electron competing side reaction, where $E^{0}\left(\mathrm{Cl}^{-} / \mathrm{Cl}_{2}\right)$ equals to $1.36 \mathrm{~V}$ vs. NHE [3].

Sulfate is another commonly used electrolyte. When 0.1 mol L-1 $\mathrm{Na}_{2} \mathrm{SO}_{4}$ at $\mathrm{pH} 3$ and $\mathrm{pH} 5.5$ are used for $\mathrm{WO}_{3}$ photoanode, lower photocurrent compared with $\mathrm{CH}_{3} \mathrm{SO}_{3} \mathrm{H}$ and $\mathrm{H}_{2} \mathrm{SO}_{4}$ is obtained, but the $\mathrm{O}_{2}$ evolution rate is largely improved (Figs $1 \mathrm{c}$ and d). The $\mathrm{O}_{2}$ Faradaic efficiency reaches $33 \%$ and $47 \%$ for $0.1 \mathrm{~mol} \mathrm{~L}^{-1} \mathrm{Na}_{2} \mathrm{SO}_{4}$ at $\mathrm{pH} 3$ and $\mathrm{pH} 5.5$, respectively. Like the case for $\mathrm{H}_{2} \mathrm{SO}_{4}$, the $\mathrm{SO}_{4}{ }^{2-}$ oxidation competes with OER for photogenerated holes.
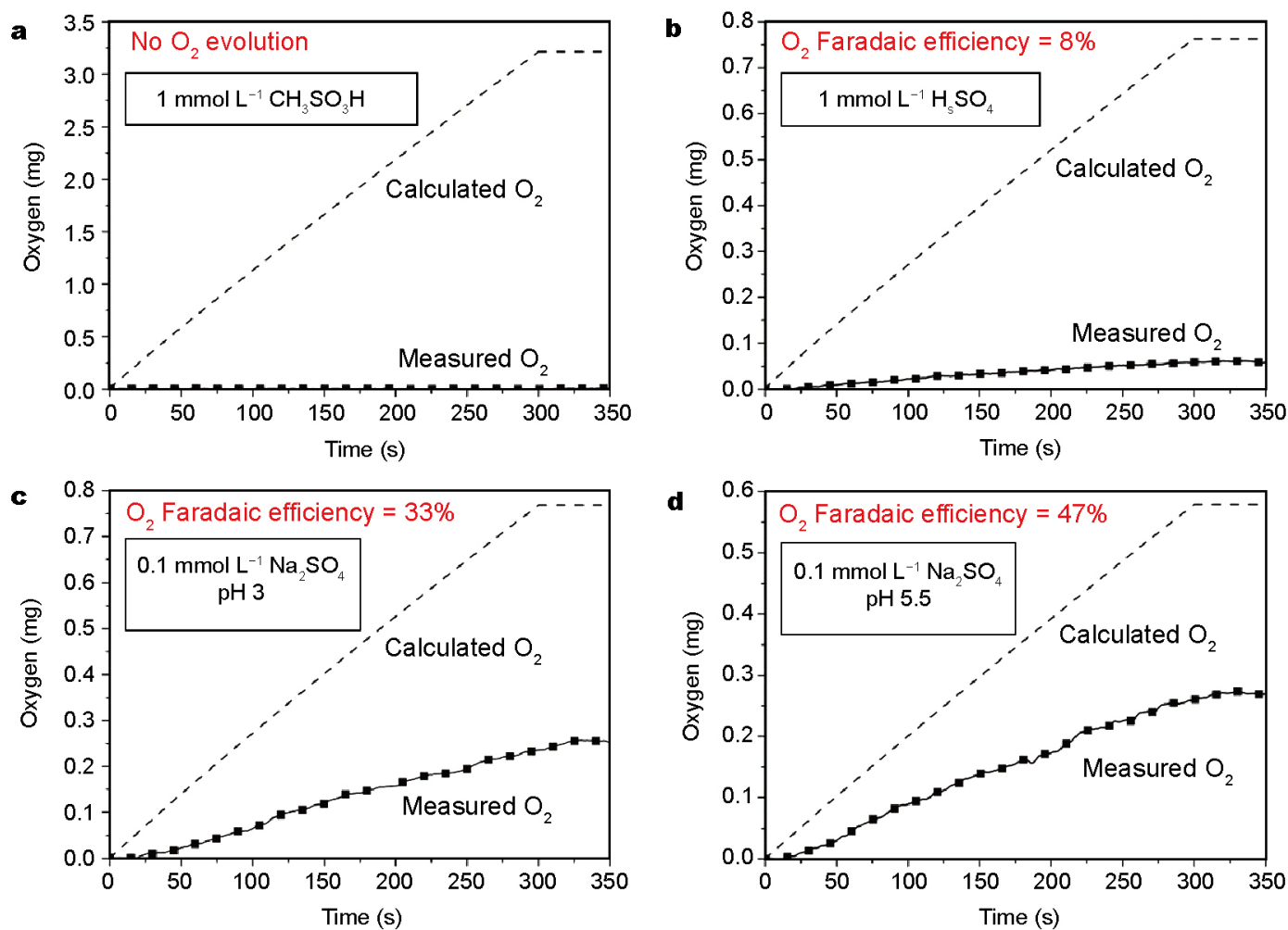

Figure 1 Measured $\mathrm{O}_{2}$ evolution amount compared with the theoretical value calculated from photocurrent for $\mathrm{WO}_{3}$ photoanodes in the four aqueous electrolytes: (a) $1 \mathrm{~mol} \mathrm{~L}^{-1} \mathrm{CH}_{3} \mathrm{SO}_{3} \mathrm{H}$, (b) $1 \mathrm{~mol} \mathrm{~L}^{-1} \mathrm{H}_{2} \mathrm{SO}_{4}$, (c) $0.1 \mathrm{~mol} \mathrm{~L}^{-1} \mathrm{Na}_{2} \mathrm{SO}_{4}$ at $\mathrm{pH} \mathrm{3}$, and (d) $0.1 \mathrm{~mol} \mathrm{~L}^{-1} \mathrm{Na}_{2} \mathrm{SO}_{4}$ at pH 5.5. Reproduced with permission from [7], Copyright 2016, Wiley-VCH. 
Another important concern is the stability of photoanode material in different electrolytes. A stability test over $20 \mathrm{~h}$ shows that the $\mathrm{WO}_{3}$ photoanode loses $44 \%$ of its initial photocurrent in $1 \mathrm{~mol} \mathrm{~L}^{-1} \mathrm{CH}_{3} \mathrm{SO}_{3} \mathrm{H}, 59 \%$ in $1 \mathrm{~mol} \mathrm{~L}^{-1}$ $\mathrm{H}_{2} \mathrm{SO}_{4}, 81 \%$ in $0.1 \mathrm{~mol} \mathrm{~L}^{-1} \mathrm{Na}_{2} \mathrm{SO}_{4}$ (pH 3), and $89 \%$ in 0.1 $\mathrm{mol} \mathrm{L}^{-1} \mathrm{Na}_{2} \mathrm{SO}_{4}$ (pH 5.5). The fact that $\mathrm{WO}_{3}$ is not stable at $\mathrm{pH}>4$ could explain the low stability in $\mathrm{Na}_{2} \mathrm{SO}_{4}$ (pH 5.5). However, the low stability of $\mathrm{WO}_{3}$ photoanode in $0.1 \mathrm{~mol}$ $\mathrm{L}^{-1} \mathrm{Na}_{2} \mathrm{SO}_{4}$ (pH 3) and highly acidic $1 \mathrm{~mol} \mathrm{~L}^{-1} \mathrm{H}_{2} \mathrm{SO}_{4}$ suggests that some new species is formed causing the deactivation. It has been suggested that the formation of persulfate $\left(\mathrm{S}_{2} \mathrm{O}_{8}{ }^{2-}\right)$ is the reason for $\mathrm{WO}_{3}$ deactivation [8]. While $1 \mathrm{~mol}$ $\mathrm{L}^{-1} \mathrm{H}_{2} \mathrm{SO}_{4}$ is expected to result in more persulfate formation than $0.1 \mathrm{~mol} \mathrm{~L}^{-1} \mathrm{Na}_{2} \mathrm{SO}_{4}(\mathrm{pH}$ 3), the stability is higher in the former electrolyte. This indicates that the formation of persulfate might not be the only cause for instability. The deactivation of $\mathrm{WO}_{3}$ has been attributed to the formation of peroxo species on the $\mathrm{WO}_{3}$ surface [9]. Hill et al. [3] also reported the existence of incomplete water oxidation to peroxide species, accompanying the oxidation of anions in electrolyte.

In conclusion, the work reported by Niederberger and co-workers underlines a very important caution that photocurrent may lead to overestimated performance of a photoanode due to the multiple reaction pathways existing in the electrolyte. The actual $\mathrm{O}_{2}$ evolution amount and the stability of the electrode should be measured to evaluate how much of the photocurrent is used to oxidize water, the electrolyte, and the anode materials, respectively. This is especially necessary for photoanode materials with a low VB edge position, such as $\mathrm{WO}_{3}$, used in electrolytes containing acidic anions with favorable oxidation kinetics. This work may further help to establish a reliable estimation methodology for photoelectrochemical performance in solar water splitting.

Received 17 November 2016; accepted 21 November 2016; published online 7 December 2016

1 Cook TR, Dogutan DK, Reece SY, et al. Solar energy supply and storage for the legacy and nonlegacy worlds. Chem Rev, 2010, 110: 6474-6502

2 Seabold JA, Choi KS. Effect of a cobalt-based oxygen evolution catalyst on the stability and the selectivity of photo-oxidation reactions of a $\mathrm{WO}_{3}$ photoanode. Chem Mater, 2011, 23: 1105-1112

3 Hill JC, Choi KS. Effect of electrolytes on the selectivity and stability of n-type $\mathrm{WO}_{3}$ photoelectrodes for use in solar water oxidation. J Phys Chem C, 2012, 116: 7612-7620

4 Mi Q, Zhanaidarova A, Brunschwig BS, et al. A quantitative assessment of the competition between water and anion oxidation at $\mathrm{WO}_{3}$ photoanodes in acidic aqueous electrolytes. Energy Environ Sci, 2012, 5: 5694-5700

$5 \mathrm{Mi}$, Coridan RH, Brunschwig BS, et al. Photoelectrochemical oxidation of anions by $\mathrm{WO}_{3}$ in aqueous and nonaqueous electrolytes. Energy Environ Sci, 2013, 6: 2646-2653

6 Kung HH, Jarrett HS, Sleight AW, et al. Semiconducting oxide anodes in photoassisted electrolysis of water. J Appl Phys, 1977, 48: 2463-2469

7 Reinhard S, Rechberger F, Niederberger M. Commercially available $\mathrm{WO}_{3}$ nanopowders for photoelectrochemical water splitting: photocurrent versus oxygen evolution. ChemPlusChem, 2016, 81: 935-940

8 Solarska R, Jurczakowski R, Augustynski J. A highly stable, efficient visible-light driven water photoelectrolysis system using a nanocrystalline $\mathrm{WO}_{3}$ photoanode and a methane sulfonic acid electrolyte. Nanoscale, 2012, 4: 1553-1556

9 Augustynski J, Solarska R, Hagemann H, Santato C. Nanostructured thin-film tungsten trioxide photoanodes for solar water and sea-water splitting. In Lionel Vayssieres (eds.). Proceedings of SPIE Solar Hydrogen and Nanotechnology, San Diego, USA, 2006, 6340: 63400J 